\title{
Hypoxic challenge flight assessments in patients with severe chest wall deformity or neuromuscular disease at risk for nocturnal hypoventilation
}

\author{
N Mestry, ${ }^{1}$ M Thirumaran, ${ }^{1} \mathrm{~J}$ M Tuggey, ${ }^{1}$ W Macdonald, ${ }^{2}$ M W Elliott ${ }^{1}$
}

${ }^{1}$ Department of Respiratory

Medicine, St James's University

Hospital, Leeds, UK:

${ }^{2}$ Department of Pulmonary

Physiology, St James's

University Hospital, Leeds, UK

Correspondence to:

Dr M W Elliott, Department of

Respiratory Medicine, St

James's University Hospital,

Beckett Street, Leeds LS9 7TF,

UK; mwelliott@doctors.org.uk

Received 15 March 2008

Accepted 19 February 2009

Published online first

23 March 2009

\begin{abstract}
Background: The British Thoracic Society (BTS) recommendations for patients with respiratory disease planning air travel suggest that an oxygen saturation $\left(\mathrm{SaO}_{2}\right)>95 \%$ precludes the need for any further assessment of the need for supplemental oxygen during flight. A hypoxic challenge test (HCT) is recommended for patients with a resting $\mathrm{SaO}_{2}$ between $92 \%$ and $95 \%$ with an additional risk factor, including kyphoscoliosis (KS) or neuromuscular disease (NMD). However, this recommendation was based on very few data.

Patients and methods: HCTs were performed on 19 adult patients with KS and/or NMD (age 22-73 years, forced expiratory volume in $1 \mathrm{~s}\left(\mathrm{FEV}_{1}\right) \quad 0.76$, forced vital capacity (FVC) $0.92, \mathrm{SaO}_{2}$ 95\%, partial pressure of arterial $\left.\mathrm{CO}_{2}\left(\mathrm{PaCO}_{2}\right) 5.7 \mathrm{kPa}\right)$ who were at risk for nocturnal hypoventilation. 15 were home ventilator users. Arterial blood gas measurements were made before and at the end of the hypoxic challenge.
\end{abstract}

Results: The results of HCTs show that the majority (15 of 19) of this cohort of patients met the criteria suggested by the BTS Standards of Care Committee for in-flight oxygen regardless of baseline $\mathrm{SaO}_{2}$.

Conclusions: This finding suggests that all patients with severe extrapulmonary restrictive lung disease should undergo assessment with HCT prior to air travel. The study confirms that even patients with a resting saturation of $>95 \%$ can desaturate significantly during hypoxic challenge. This study does not address the question of whether desaturation at altitude has any adverse consequences for patients. A decision as to whether it is safe for a patient to fly should be made by an experienced clinician and based on a number of factors, which should include previous travel experience, the patient's overall condition and the results of an HCT.

In 2002 the British Thoracic Society (BTS) Standards of Care Committee published recommendations for managing patients with respiratory disease planning air travel. ${ }^{1}$ It was recommended that assessment should include pulse oximetry, with arterial blood gas analysis being preferred if hypercapnia is suspected. Supplemental oxygen during flight is not recommended for patients with a resting oxygen saturation $\left(\mathrm{SaO}_{2}\right)$ at sea level of $>$ $95 \%$ or for those with a saturation between $92 \%$ and $95 \%$, without an additional risk factor. For those with an $\mathrm{SaO}_{2}$ between $92 \%$ and $95 \%$ at sea level and an additional risk factor, a hypoxic challenge test (HCT) is recommended. If the $\mathrm{SaO}_{2}$ is $<92 \%$, supplemental oxygen should be advised for use throughout flight. Preflight assessment is recommended for a variety of specific groups of patients, including those with severe restrictive disease (including chest wall and respiratory muscle disease) with hypoxaemia and/or hypercapnia; these patients should therefore have an HCT if their resting saturation is $\leqslant 95 \%$. If during the hypoxic challenge the partial pressure of arterial $\mathrm{O}_{2}\left(\mathrm{PaO}_{2}\right)$ falls below $6.6 \mathrm{kPa}$, supplemental oxygen is recommended during flight; if it remains above $7.4 \mathrm{kPa}$, supplemental oxygen is not needed, with values in between considered borderline. However, these recommendations for patients with neuromuscular disease and kyphoscoliosis were made on anecdotal evidence and little data.

We therefore conducted an exploratory study to assess whether HCTs are really necessary in this patient group and to evidence the recommendation of the BTS Standards of Care Committee. The study was not designed to assess the effects of hypoxia but rather to establish whether the recommendations made in the BTS guidelines were appropriate.

\section{PATIENTS AND METHODS}

Ethical approval was obtained from the Leeds (East) Teaching Hospitals NHS Trust.

Nineteen patients attending a respiratory failure clinic (16 idiopathic kyphoscoliosis, 4 neuromuscular disease, 1 previous polio) gave written informed consent to participate and underwent HCTs. Thirteen were male and eight female, age range $22-73$ years (median 58 years). The median forced expiratory volume in $1 \mathrm{~s}\left(\mathrm{FEV}_{1}\right)$ was 0.66 litres (range 0.3-1.0 litres), median forced vital capacity (FVC) 0.81 litres (range 0.3-1.2 litres), and median $\mathrm{SaO}_{2}$ 95\% (range 92-99\%). Fifteen patients used ventilators each night during sleep at home. The patients were typical of patients attending the clinic except that more severely disabled patients were not recruited because of the complexities of getting them back for the study. They are also less likely to fly.

For the HCTs, patients were seated at rest and breathed a $15 \%$ oxygen gas mix using a Douglas bag and a non-rebreathe valve and mouthpiece, ${ }^{2}$ or a nitrogen-driven gas mixture using a $40 \%$ Venturi mask $^{3}$ for $20 \mathrm{~min}$. The $\mathrm{SaO}_{2}$ was monitored throughout the test, which was terminated if the $\mathrm{SaO}_{2}$ fell below $86 \%$. Arterial blood gas tensions were recorded before and at the end of the test (Gem 3000, manufactured by Instrumentation Laboratory, Birchwood, Warrington, UK)

A test was defined as positive if $\mathrm{PaO}_{2}$ was $<6.6 \mathrm{kPa}$, borderline if $\mathrm{PaO}_{2}$ was $6.7-7.4 \mathrm{kPa}$ and negative if $\mathrm{PaO}_{2}$ was $>7.4 \mathrm{kPa} .{ }^{1}$ 
Table 1 Results of the hypoxic challenge test

\begin{tabular}{|c|c|c|}
\hline Baseline $\mathrm{SaO}_{2}$ & $>95 \%, 12$ patients & 92-95\%, 7 patients \\
\hline Positive test & 6 patients & 5 patients \\
\hline $\mathrm{PaO}_{2}<6.6 \mathrm{kPa}$ & $50 \%$ & $71 \%$ \\
\hline Borderline test & 3 patients & 1 patient \\
\hline $\mathrm{PaO}_{2} 6.6-7.4 \mathrm{kPa}$ & $25 \%$ & $14.5 \%$ \\
\hline Negative test & 3 patients & 1 patient \\
\hline $\mathrm{PaO}_{2}>7.4 \mathrm{kPa}$ & $25 \%$ & $14.5 \%$ \\
\hline
\end{tabular}

$\mathrm{PaO}_{2}$, partial pressure of arterial $\mathrm{O}_{2} ; \mathrm{SaO}_{2}$, oxygen saturation.

\section{RESULTS}

All 19 patients completed the test without any adverse effects. The results are shown in table 1 . Five HCTs were terminated prematurely because of a fall in $\mathrm{SaO}_{2}$ to $<85 \%$ (3 of these had baseline $\mathrm{SaO}_{2}>95 \%$ ).

Fifty per cent of patients with a resting $\mathrm{SaO}_{2}>95 \%$, who would not be deemed to require in-flight oxygen, and the majority (71\%) of patients with a borderline baseline $\mathrm{SaO}_{2}(92-95 \%)$ would be recommended to have supplemental oxygen on HCT criteria. Only four patients would definitely not require in-flight oxygen on the basis of the HCT result.

The $\mathrm{PaO}_{2}$ and $\mathrm{PaCO}_{2}$ at baseline and during hypoxic challenge are shown in figs 1 and 2 for the patients $(n=15)$, who had arterial blood gases measured at both time points. $\mathrm{PaO}_{2}$ fell from 10.3 (1.3) $\mathrm{kPa}$ at baseline to 6.7 (0.5) $\mathrm{kPa}$ during the hypoxic challenge (mean difference $-3.6 \mathrm{kPa}, 95 \%$ CI 2.9 to $4.3 \mathrm{kPa}, \mathrm{p}<0.0001)$. There was no significant change in $\mathrm{PaCO}_{2}$, baseline 6.0 (0.5), hypoxic challenge 5.9 (0.6) (mean difference $0.14 \mathrm{kPa}, 95 \% \mathrm{CI}-0.18$ to $+0.45, \mathrm{p}=0.36)$. The alveolararterial oxygen tension $\left(\mathrm{A}-\mathrm{aO}_{2}\right)$ gradient narrowed from baseline $2.1(1.0) \mathrm{kPa}$ to $1.0(0.7) \mathrm{kPa}$ during hypoxic challenge (mean difference $1.2 \mathrm{kPa}, 95 \%$ CI 0.55 to $1.9 \mathrm{kPa}, \mathrm{p}=0.002$ ).

There was no consistent response between the change in $\mathrm{PaO}_{2}$ and the change in $\mathrm{PaCO}_{2}$ (fig 3).

\section{DISCUSSION}

Our data support the recommendations made by the BTS Standards of Care Committee with respect to the need for hypoxic challenge testing in patients with an $\mathrm{SaO}_{2}$ between $92 \%$ and $95 \%$ and with the risk factor of chest wall deformity or respiratory muscle weakness. In addition, however, these data suggest that all patients with severe extra pulmonary restrictive lung disease secondary to chest wall deformity or neuromuscular disease should have hypoxic challenge testing, regardless of the baseline $\mathrm{SaO}_{2}$, as $75 \%$ of patients with an $\mathrm{SaO}_{2}>95 \%$ had a positive or borderline test.

The observation that the $\mathrm{A}-\mathrm{aO}$ gradient narrows is interesting and is likely to be due to improved $\mathrm{VQ}$ (ventilation- perfusion) matching due to hypoxic vasoconstriction. ${ }^{4}$ The $\mathrm{A}-\mathrm{aO}_{2}$ gradient does widen with increasing fractional inspired $\mathrm{O}_{2}\left(\mathrm{FiO}_{2}\right)$ and narrow in hypoxia, even in healthy individuals. ${ }^{5}$ These patients are unable, because of their severe extrapulmonary restriction, to mount an adequate ventilatory response to compensate for the effects of breathing a hypoxic gas mixture. The average change in $\mathrm{PaCO}_{2}$ was a $0.2 \mathrm{kPa}$ fall - a much larger change would be needed to maintain adequate oxygenation. There was no consistent relationship between the change in $\mathrm{PaO}_{2}$ and $\mathrm{PaCO}_{2}$ during HCT or between patients who had a positive HCT or those with an equivocal or negative result. This suggests that the response to hypoxia is a complex interaction between the ability to increase ventilation and to change VQ relationships. Patients with chest wall deformity and neuromuscular disease were grouped together; the pathophysiology of respiratory failure is different, but the

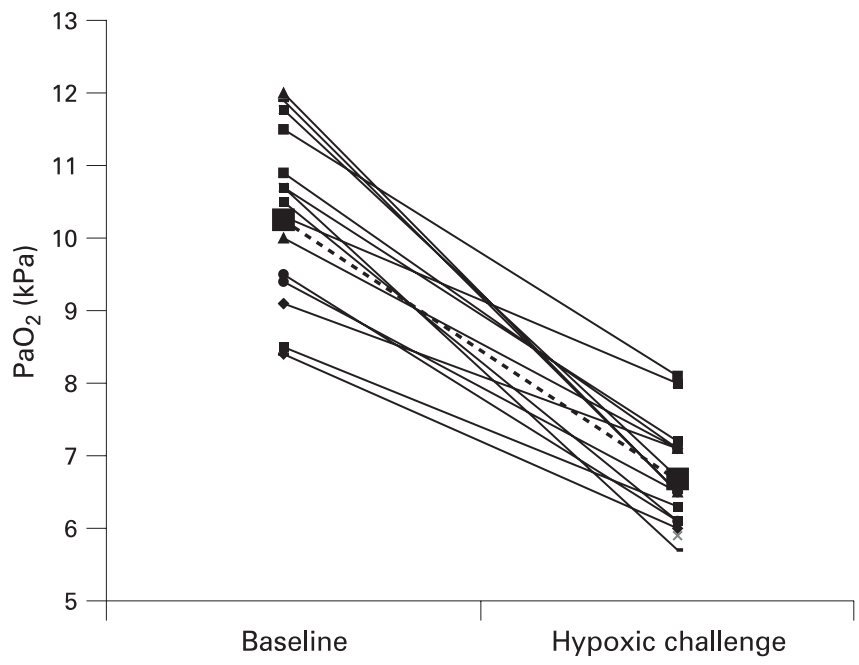

Figure 1 Partial pressure of arterial $\mathrm{O}_{2}\left(\mathrm{PaO}_{2}\right)$ at baseline and following hypoxic challenge. Individual patient data are shown. The dashed line indicates mean data.

inability to increase ventilation, or change $\mathrm{VQ}$, in response to hypoxia is common to both patient groups.

However, it is not known whether these patients are really at risk from the levels of hypoxia that are seen when flying in commercial aircraft. There are few data about the effects of air travel on patients with respiratory disease, and most of the recommendations are based upon theoretical considerations and consensus opinion. Interestingly the BTS Standards of Care Committee recommendations on managing passengers with respiratory disease planning air travel were described as a "statement" rather than a "guideline". This is different from all the other recommendations made by the Standards of Care Committee, which are described as "guidelines". The authors stated that there was insufficient evidence to produce formal guidelines and that the recommendations, based on a review of the literature, aimed to provide "practical advice to respiratory physicians". It is of note that the only recommendation with level A evidence related to the equivalence of spacer devices and nebulisers.

Many clinicians looking after significant numbers of patients with severe extrapulmonary restrictive disease are sceptical about the need for these patients to be supplied with oxygen during flight, based upon years of experience of their patients flying. Many patients have flown without the provision of supplementary oxygen; others have had it available, but not used it during flight. There have been no systematic studies of the effects of air travel upon these patients. The BTS study of the effects of travel upon patients with respiratory disease showed that $17 \%$ of patients experienced respiratory distress during flight. However, it is not known whether this was a consequence of hypoxia or because of the general discomfort associated with air travel for an individual, who as part of everyday life may already be experiencing a degree of discomfort. The study population did not include any ventilator users or patients with severe extrapulmonary restrictive disorders. There is no doubt that the recommendation that a patient receives oxygen during air travel complicates their travel arrangements and often results in significant extra expense.

Without ventilatory support the patients described in this study experience more marked oxygen desaturation than that seen during a 20 min HCT each night during sleep, ${ }^{6}$ though this will be much improved by non-invasive ventilation (NIV). ${ }^{8}$ 


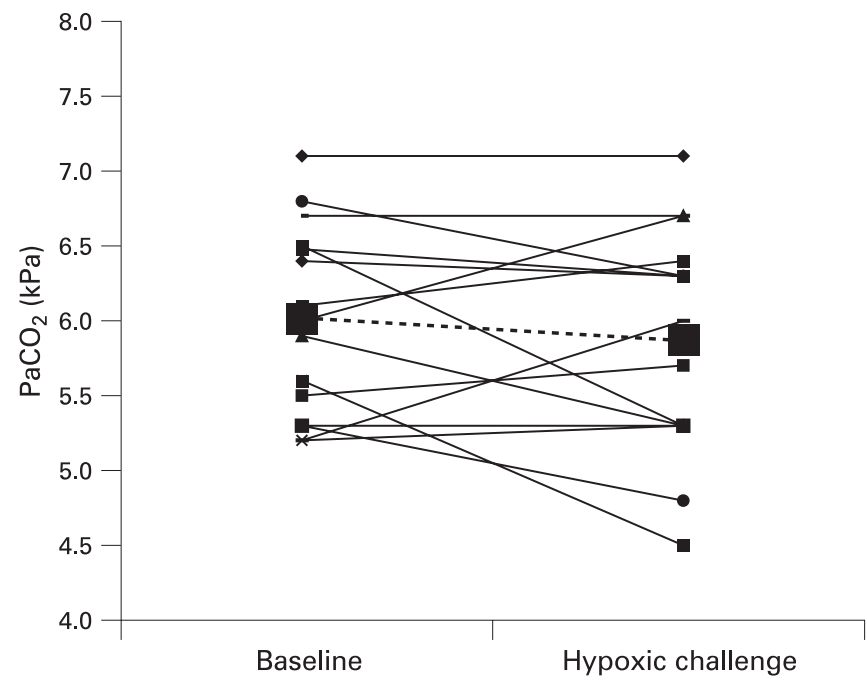

Figure 2 Partial pressure of arterial $\mathrm{CO}_{2}\left(\mathrm{PaCO}_{2}\right)$ at baseline and following hypoxic challenge. Individual patient data are shown. The dashed line indicates mean data.

It is likely that these patients are acclimatised to some of the short-term adverse effects of hypoxia. Paradoxically this may be less for patients well established on NIV, who are no longer experiencing such severe nocturnal desaturation. However, despite effective NIV, oxygenation is seldom normal overnight and these patients will still experience intermittent hypoxia during sleep and exercise.

The question still remains as to whether these patients require any sort of special treatment during flight. This study does not address this question. What should clinicians recommend for these patients? If patients desaturate during a hypoxic challenge, and experience respiratory distress, it would certainly be reasonable to suggest that the patient receive supplementary oxygen during flight. However, the majority of patients do not experience any respiratory distress during an HCT. Must all of these patients receive supplementary oxygen if they are to be allowed to fly? The evidence does not support this and it would seem reasonable to allow the patient to make an informed choice based on knowledge of the fact that it is likely that they will desaturate during flight, but that this will be to a level that many of them will already have experienced each night during sleep and during exercise. However, patients will sometimes require a letter from a doctor saying that it is safe for them to fly. Interestingly the suggestion that oxygen is necessary during flight is often a trigger for this. Doctors are increasingly concerned about being held legally accountable for advice that they give, leading to defensive practice. The responsibility of the clinician is to weigh risk and benefit, and advise others accordingly. Most doctors would feel uncomfortable giving advice that was contrary to guidelines, which have usually involved a comprehensive review of the available literature, and been subject to debate amongst experts and extensively peer reviewed. However, with regard to the provision of supplementary oxygen during flight, the evidence that it is needed is so weak and the Standards of Care Committee only felt able to make a "statement" of recommendations rather than a "guideline". As a result, an experienced clinician has to make a recommendation for each individual patient, based upon that patient's previous experience of air travel, the results of an HCT and the patient's overall clinical condition, including the presence of comorbidities.

For those patients who are deemed to require supplementary oxygen, the BTS statement recommends that patients who

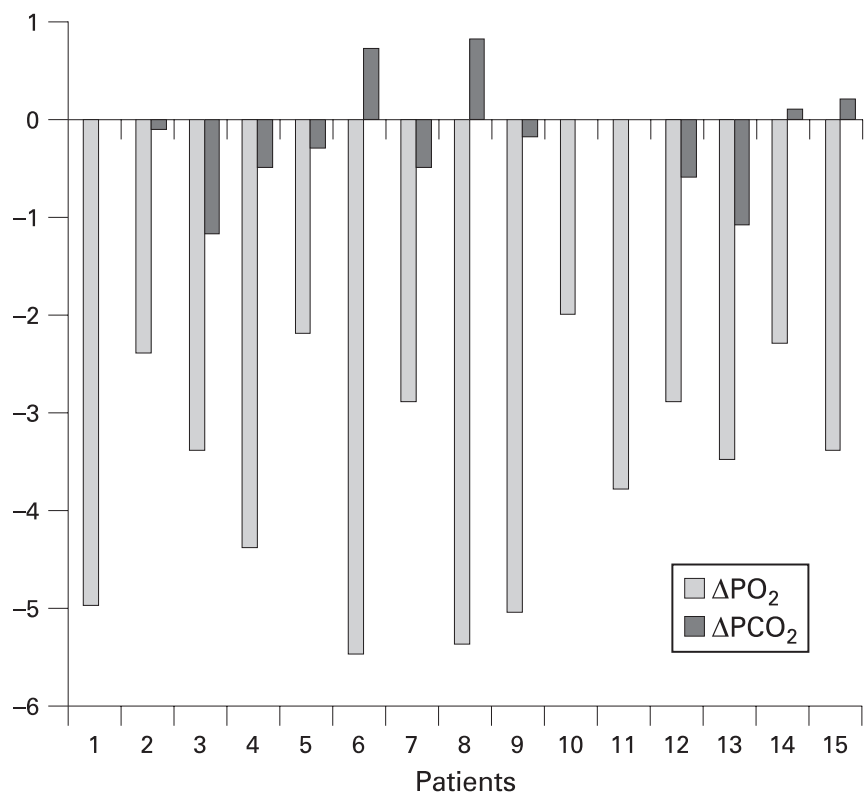

Figure 3 Change from baseline in partial pressure of arterial $\mathrm{O}_{2}\left(\mathrm{PaO}_{2}\right)$ and partial pressure of arterial $\mathrm{CO}_{2}\left(\mathrm{PaCO}_{2}\right)$ for each patient.

desaturate during a hypoxic challenge should be provided with oxygen once the aircraft reaches cruising altitude at a flow rate of 2 litres per minute. The intention is to reproduce the oxygen concentration at sea level and therefore there should not be a risk of worsening hypercapnia. Alternatively, if the airline will allow, the ventilator can be used during flight. This will require a dry cell battery, and patients would be advised to discuss this with the airline before travel.

In conclusion, these data confirm that patients with severe extrapulmonary restrictive chest wall deformity or neuromuscular disease are at risk of more severe hypoxia during a hypoxic challenge, even when baseline saturation is near normal. Further studies are needed to ascertain if these patients really are at increased risk from the effects of hypoxia during flying and whether patients with milder restriction are also at risk of more marked hypoxia during an HCT. Until then, experienced clinicians should advise patients, on a case by case basis, taking into account previous travel experience, the results of an HCT and the patient's overall condition.

Competing interests: None.

Ethics approval: Ethical approval was obtained from the Leeds (East) Teaching Hospitals NHS Trust.

\section{REFERENCES}

1. British Thoracic Society Standards of Care Committee. Managing passengers with respiratory disease planning air travel: British Thoracic Society recommendations Thorax 2002; 57:289-304.

2. Dillard TA, Moores LK, Bilello KL, et al. The preflight evaluation. A comparison of the hypoxia inhalation test with hypobaric exposure. Chest 1995;107:352-7.

3. Vohra KP, Klocke RA, Vohra KP, et al. Detection and correction of hypoxemia associated with air travel. Am Rev Respir Dis 1993;148:1215-9.

4. Swenson ER, Robertson HT, Hlastala MP, et al. Effects of inspired carbon dioxide on ventilation-perfusion matching in normoxia, hypoxia, and hyperoxia. Am J Resp Crit Care Med 1994;149:1563-9.

5. Hoffstein V, Duguid N, Zamel N, et al. Estimation of changes in alveolar-arterial oxygen gradient induced by hypoxia. J Lab Clin Med 1984;104:685-92.

6. Guilleminault C, Kurlan G, Winkle R, et al. Severe kyphoscoliosis, breathing and sleep. The Quasimodo syndrome during sleep. Chest 1981;79:626-30.

7. Bye PT, Ellis ER, Issa FG, et al. Respiratory failure and sleep in neuromuscular disease. Thorax 1990;45:241-7.

8. Ellis ER, Grunstein RR, Chan $\mathrm{S}$, et al. Noninvasive ventilatory support during sleep improves respiratory failure in kyphoscoliosis. Chest 1988;94:811-5. 